\section{Endoscopic ultrasound-guided histological diagnosis of a mucinous non-neoplastic pancreatic cyst using a specially designed through-the-needle microforceps}

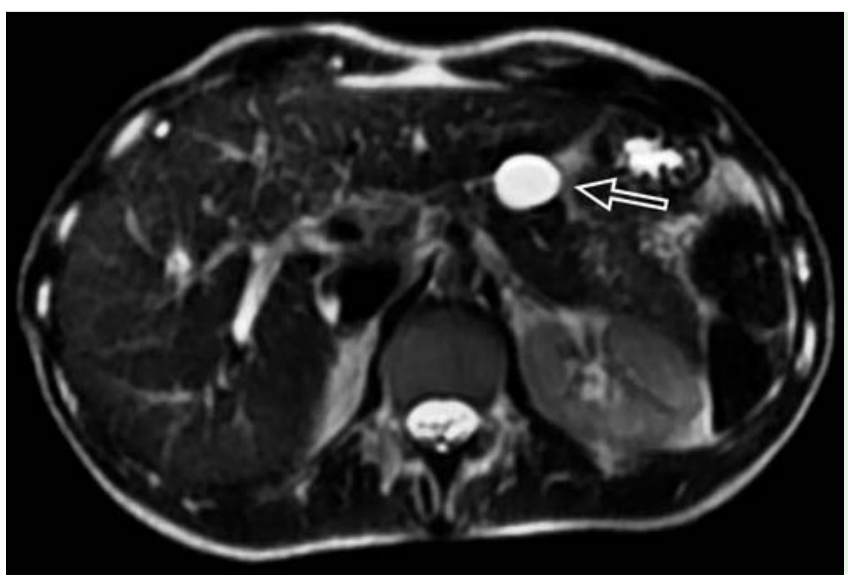

Fig. 1 Axial T2 weighted magnetic resonance image showing a $25 \times$ $20 \mathrm{~mm}$ unilocular pancreatic neck cystic lesion without communication with the Wirsung duct (arrow).
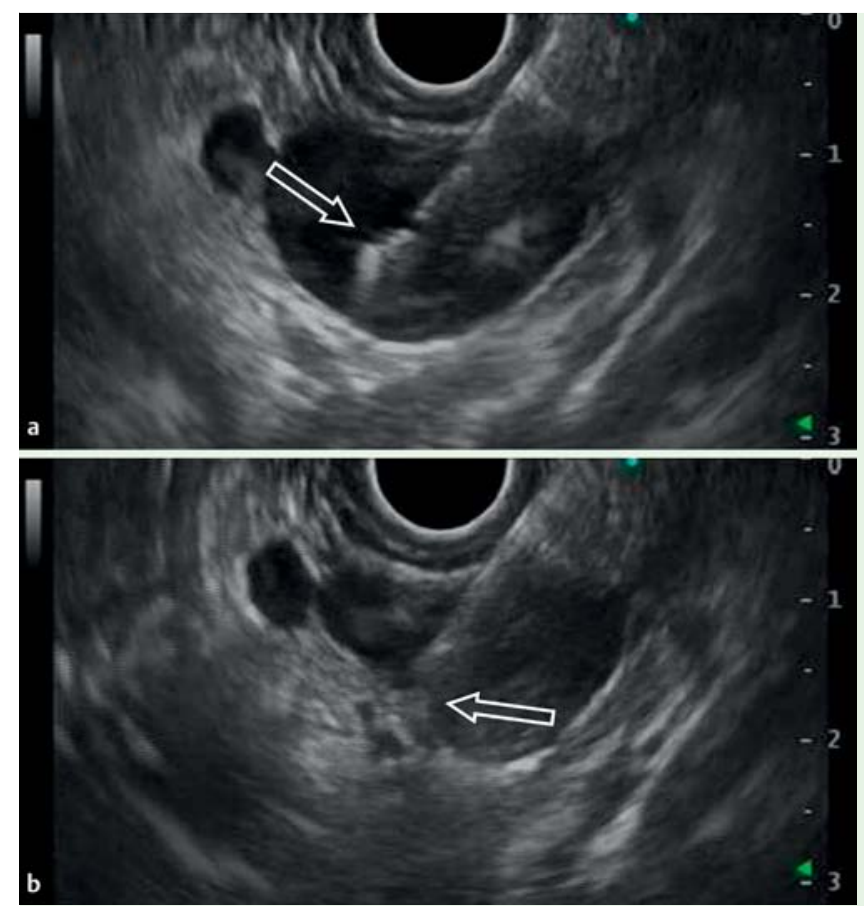

Fig. 3 Tissue acquisition using through-theneedle microforceps. a Endoscopic ultrasound-guided opening of the cups of the through-the-needle microforceps inside the pancreatic cyst (arrow). b The "tent sign" representing the cystic wall (arrow) grasped by the biopsy forceps and pulled back in order to acquire the tissue sample.
Solitary uniloculated pancreatic cysts pose a major diagnostic dilemma. Cystic fluid carcinoembryonic antigen (CEA) concentration and cytology have low sensitivity in distinguishing mucinous from non-mucinous cysts [1], leading to frequent misdiagnoses and unnecessary surgical interventions [2]. Recently evaluated molecular markers seem very accurate, but they are not widely available in clinical practice [3].
We present the case of a 49-year-old woman who was incidentally discovered to have a 25-mm cystic pancreatic neck lesion, without apparent communication with the Wirsung duct ( $\bullet$ Fig. 1, $\bullet$ Video 1 ). At endoscopic ultrasound (EUS), the cyst had no septa, normal walls, and no mural nodules.

Prophylactic intravenous antibiotics were administered and EUS-guided fine-needle aspiration (FNA) was performed using a 19 -gauge needle. After $2 \mathrm{~mL}$ of fluid were

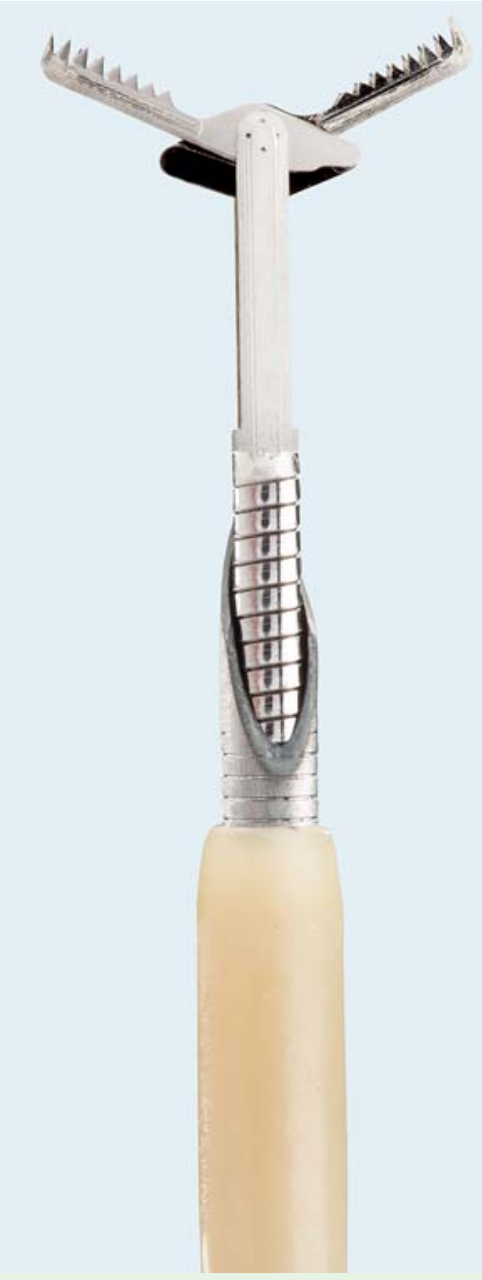

Fig. 2 View of the novel through-the-needle microforceps (Moray microforceps; US Endoscopy, Mentor, Ohio, USA) protruding from a standard 19-gauge fine-needle aspiration needle, with its cups opened. The microforceps has an outer diameter of $0.8 \mathrm{~mm}$, a jaw opening width of $4.3 \mathrm{~mm}$, serrated jaws designed to effectively grasp tissue, and a spring sheath to increase its flexibility. Photograph used with permission from US Endoscopy.

aspirated, a toothed microforceps (Moray microforceps; US Endoscopy, Mentor, Ohio, USA) ( $\bullet$ Fig. 2 ), designed specifically for tissue acquisition through a 19-gauge FNA needle, was inserted through the needle into the cyst cavity. Under EUS guidance, the microforceps was opened, pushed against the cyst wall, and then 


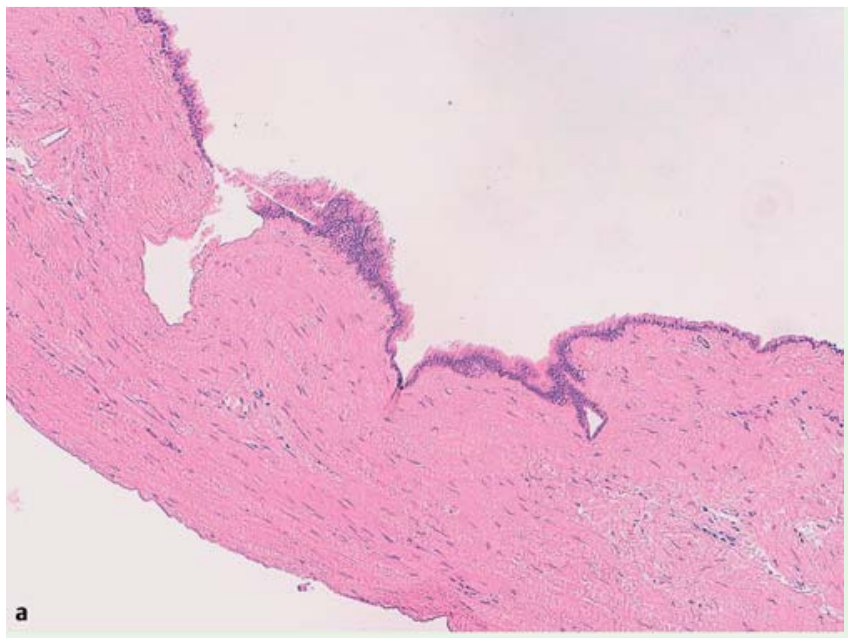

Fig. 4 Photomicrographs of the samples collected using the novel through-the-needle microforceps. Histology revealed a fibrous wall lined by tall, columnar, mucin-producing, epithelial cells (duct-type epithelium) consistent with the diagnosis of mucinous non-neoplastic pancreatic cyst (hematoxylin and eosin staining). a Low-power field. b High-power field.

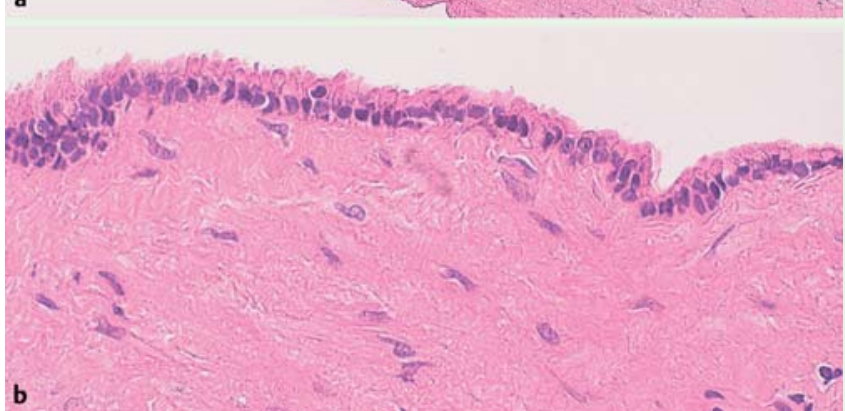

closed in order to obtain tissue samples ( $\bullet$ Fig. 3). Two bites of the cyst wall were taken using the biopsy microforceps, and the specimens were placed directly into formalin for histological examination. No procedural or delayed complications occurred.

Cystic fluid amylase and CEA concentrations were $692 \mathrm{U} / \mathrm{L}$ and $491 \mathrm{ng} / \mathrm{mL}$, respectively. Histological examination revealed a fibrous wall lined by tall, columnar, mucinproducing, epithelial cells ( $\bullet$ Fig.4), consistent with the diagnosis of a mucinous non-neoplastic cyst.

This case clearly illustrates the diagnostic challenge of pancreatic cysts. The novel through-the-needle microforceps allowed the acquisition of tissue that showed all of the histological criteria needed for a diagnosis of mucinous non-neoplastic cyst [4]. These results allowed us to choose the most appropriate management for this patient, which, importantly, would have been different if based on CEA results alone. Mucinous non-neoplastic cysts are, in fact, benign conditions, without any malignant potential and for which both surgery and surveillance are not necessary.
Endoscopy_UCTN_Code_TTT_1AS_2AD

Competing interests: None

Fabia Attili ${ }^{1}$, Danilo Pagliari ${ }^{1,2}$, Mihai Rimbaș ${ }^{1,3}$, Frediano Inzani ${ }^{4}$, Maria Gabriella Brizi ${ }^{5}$, Guido Costamagna ${ }^{1}$, Alberto Larghi ${ }^{1}$

${ }^{1}$ Digestive Endoscopy Unit, Catholic University, Rome, Italy Gastroenterology, Catholic University, Rome, Italy

${ }^{3}$ Department of Gastroenterology, Colentina Clinical Hospital, Carol Davila University of Medicine, Bucharest, Romania

${ }^{4}$ Department of Pathology, Catholic University, Rome, Italy

${ }^{5}$ Department of Radiology, Catholic University, Rome, Italy
2 Department of Internal Medicine and

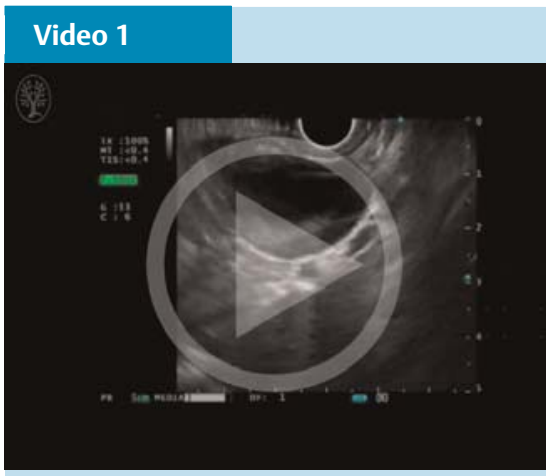

Endoscopic ultrasound-guided tissue acquisition from pancreatic cyst wall using a novel through-the-needle microforceps.

\section{References}

1 Thornton GD, McPhail MJ, Nayagam S et al. Endoscopic ultrasound guided fine needle aspiration for the diagnosis of pancreatic cystic neoplasms: a meta-analysis. Pancreatology 2013; 13: 48-57

2 Jais B, Rebours V, Malleo G et al. Serous cystic neoplasm of the pancreas: a multinational study of 2622 patients under the auspices of the International Association of Pancreatology and European Pancreatic Club (European Study Group on Cystic Tumors of the Pancreas). Gut 2016; 65: 305-312

3 Springer S, Wang Y, Dal Molin M et al. A combination of molecular markers and clinical features improve the classification of pancreatic cysts. Gastroenterology 2015; 149: $1501-1510$

$4 \mathrm{Kim}$ YS, Cho JH. Rare nonneoplastic cysts of pancreas. Clin Endosc 2015; 48: 31-38

Bibliography

Dol http://dx.doi.org/

10.1055/s-0042-108194

Endoscopy 2016; 48: E188-E189

(c) Georg Thieme Verlag KG

Stuttgart · New York

ISSN 0013-726X

Corresponding author

Alberto Larghi, MD, PhD

Digestive Endoscopy Unit

Catholic University

Largo A. Gemelli 8

00168, Rome

Italy

Fax: +39-06-30156581

alberto.larghi@yahoo.it 